\title{
Educação do Campo e pluralidade de saberes
}

\author{
Cícero da Silva ${ }^{1}$, Gustavo Cunha de Araújo ${ }^{2}$ \\ ${ }^{1}$ Universidade Federal do Tocantins - UFT, Departamento de Educação do Campo. Avenida Nossa Senhora de \\ Fátima, 1588, Centro. Tocantinópolis, Brasil. rbec@uft.edu.br. ${ }^{2}$ Universidade Federal do Tocantins - UFT.
}

A Revista Brasileira de Educação do Campo - RBEC, ISSN 2525-4863, periódico do Departamento de Educação do Campo, da Universidade Federal do Tocantins, campus de Tocantinópolis, lança o seu primeiro número do volume 3, referente ao primeiro semestre de 2018. Este número traz 15 artigos, aprovados dentre os manuscritos recebidos ao longo do ano de 2017 e 2018.

Os artigos aqui socializados reforça o crescimento de pesquisas a respeito da Pedagogia da Alternância, escolas do campo, povos indígenas, políticas públicas, movimentos sociais, práticas pedagógicas e formação de professores, de diferentes estados brasileiros e de outros países também, o que contribui para que a produção de conhecimento nesse âmbito se fortaleça e se amplie na educação brasileira.

Abrimos este número com o artigo "Martin Rodriguez Vivanco e a Sociologia da Educação em Cuba", da autora Lídice Mesa Gómez (Universidade de Artemisa, Cuba), cujo objetivo da pesquisa é analisar a contribuição de Martin Rodriguez Vivanco para o desenvolvimento da Sociologia da Educação em Cuba durante a República neocolonial e o significado de seus conceitos para a atualidade. Os resultados da pesquisa revelaram a visão de Vivanco sobre a teoria da Sociologia da Educação, refletida no tratamento que fez seu assunto, sua relação com outras ciências, suas principais categorias, entre outros, que são o ponto de partida para o estudo desta ciência no país e servir para esclarecer e apoiar as raízes da pedagogia cubana.

O segundo artigo, intitulado "Memória educacional no município de Enéas Marques-PR: décadas de (1960-1990) - das escolas rurais à nuclearização", de autoria de Maricélia Aparecida Nurmberg e André Paulo Castanha (UNIOESTE), investiga a história da Educação do Município de Enéas Marques, situado no Sudoeste do Paraná, entre as décadas de 1960 e 1990, período em que o número de escolas rurais era muito expressivo. Os achados da pesquisa mostraram que estas escolas eram em sua maioria multisseriadas, funcionando em dois períodos, sendo atendidas por um ou dois professores. Todavia, a partir da década de 1990, a gestão municipal iniciou o processo de fechamento/nuclearização destas escolas e os estudantes passaram a utilizar do transporte escolar, obrigando-os a estudar em escolas urbanas, fazendo com que a identidade rural fosse se perdendo.

Em "O tempo aldeia: construindo uma nova prática pedagógica”, de Ribamar Ribeiro Junior, Laécio Rocha de Sena e William Bruno Silva Araújo (UFMG, UNIFESSPA e

\begin{tabular}{|l|l|l|l|l|l|l|l|}
\hline Rev. Bras. Educ. Camp. & Tocantinópolis & v. 3 & n. 1 & p. 01-04 & jan./abr. & 2018 & ISSN: 2525-4863 \\
\hline
\end{tabular}


IFPA), o propósito da investigação é estabelecer diálogo com o pensamento descolonial na educação a partir da experiência do Curso Técnico em Agroecologia do Campus Rural de Marabá, do Instituto Federal do Pará (IFPA). Nesse curso, o percurso formativo integra dois tempos de estudo: o Tempo Escola e o Tempo Aldeia, caracterizado como "alternância pedagógica". A pesquisa mostrou que essa lógica da alternância parte do estudo da realidade "concreta", possibilitando aos educandos articulação dos conhecimentos tradicionais e os técnico-científicos relacionados às dimensões políticas, históricas, naturais. Nessa perspectiva, parte-se da proposta de educação descolonial e o tempo aldeia se mostrou central na estratégia de se pensar e repensar formas de educação "outras", aquelas da modernidade.

No artigo "Educação do Campo e material didático: uma análise de livros didáticos de História", de autoria de Cícero da Silva e Ilário Dias Cardoso Filho (UFT), o objetivo da pesquisa é analisar dois Livros Didáticos de História (LDH) utilizados no Ensino Fundamental ( $6^{\circ}$ ano) em escolas do campo situadas no município de Tocantinópolis-TO. As análises desse material didático focalizam: (1) conteúdos; (2) atividades; (3) interação professor-aluno; e as (4) imagens. Tendo em vista a realidade das escolas do campo e do contexto social, político e econômico em que vivem os camponeses, o estudo revelou que apenas um dos LDH analisados atende aos princípios defendidos pela Educação do Campo.

Já "Educação Contextualizada para a convivência com o Semiárido Brasileiro como uma prática emancipadora", artigo de autoria de Luana Patrícia Costa Silva, Albertina Maria Ribeiro Brito e Alexandre Eduardo de Araújo (UFPB), tem como principal objetivo elucidar práticas pedagógicas que esboçam uma relação de Educação para Convivência com o Semiárido Brasileiro, a partir da experiência da Escola Plínio Lemos Escola da Terra, localizada no assentamento Zé Marcolino, Prata-PB. Estas práticas são visualizadas na prática das educadoras que possibilitam um contexto educativo pautado no ensinar e aprender coletivos. Desta forma, a pesquisa identificou ações emancipadoras que descortinam os estereótipos destinados às regiões Semiáridas e aos seus sujeitos, na medida em que passam a ressignificar suas identidades e construir uma nova concepção educativa, pautada na emancipação e na autonomia.

Em seguida, o artigo "O Curso Técnico em Cooperativismo realizado pelo PRONERA: uma análise baseada na Abordagem das Capacitações”, de Conceição Coutinho Melo e Paulo Dabdab Waquil (INCRA e UFRGS), traz resultados de uma pesquisa sobre o Curso Técnico em Cooperativismo (TAC), que surge na década de 90 como demanda do MST em formar técnicos para atuar nas cooperativas dos assentamentos rurais de Reforma Agrária. Atualmente, o curso é desenvolvido por meio do Programa Nacional de Educação na Reforma Agrária - PRONERA, sob o paradigma da Educação do Campo. Considerando que se pretendeu investigar se esse curso contribui para a expansão das capacitações de seus egressos e para o desenvolvimento dos assentamentos rurais, a pesquisa revelou que todos os entrevistados continuaram seus estudos e atuaram, depois de formados, em entidades ligadas aos assentamentos. O processo formativo do TAC tem contribuído na expansão da liberdade dos egressos.

Em "As relações entre escola e comunidade na concepção de professores que atuam na Educação do Campo", artigo das autoras Jéssica Pauletti e Sandra Maria Wirzbicki (UFFS), o objetivo é compreender as percepções das relações entre escola e comunidade a partir de práticas e conhecimento da Educação do Campo entre professores que atuam em escolas do Ensino Médio da região Sudoeste do Paraná. Os resultados do estudo possibilitaram organizar categorias que indicam a existência de dificuldades na elaboração do planejamento por parte dos professores e uma participação efetiva da comunidade, assim como entendimentos limitados acerca da localidade e organização do currículo. Apesar de dificuldades, existem tentativas, como a realização de feiras e visitas às propriedades rurais, além da compreensão do quão é necessário desenvolver temáticas do cotidiano dos alunos nas

\begin{tabular}{|l|l|l|l|l|l|l|l|}
\hline Rev. Bras. Educ. Camp. & Tocantinópolis & v. 3 & n. 1 & p. 01-04 & jan./abr. & 2018 & ISSN: 2525-4863 \\
\hline
\end{tabular} 
aulas, possibilitando abordagens significativas dos conteúdos. Ainda, a partir das análises, emerge uma problemática maior que envolve os professores, a escola e a comunidade: trata-se da Educação do Campo com traços fortes da Educação Rural.

No artigo intulado "O Ensino da Física na Educação do Campo: descolonizadora, instrumentalizadora e participativa", de autoria de Roberto Gonçalves Barbosa (UFPR), é discutido o caráter epistemológico crítico da Física sob o viés do colonialismo a partir da qual se apresenta as possíveis contribuições do ensino desta disciplina no contexto da Educação do Campo, segundo o autor. Esta pesquisa possibilitou compreender uma abordagem metodológica desenvolvida com duas turmas de licenciandos do curso de Educação do Campo - Ciências da Natureza da Universidade Federal do Paraná, Setor Litoral.

Na pesquisa seguinte, de autoria de Mônica de Almeida Santos, Alcione de Almeida Santos, Maria Célia Santana Orrico e Mariana Martins de Meireles (UFRB), intitulado "Retratos contemporâneos da Educação do Campo: movimentos investigativos no Vale do Jiquiriçá-BA", as autoras relatam um estudo desenvolvido no povoado do Serrote, área rural do município de Elísio Medrado-BA, no âmbito dos estudos efetivados pelo Observatório em Educação do Vale do Jiquiriçá (OBSERVALE/UFRB), que tem como finalidade ampliar estudos e promover debates sobre a Educação do Campo no Território do Vale do Jiquiriçá. Dentre outros resultados encontrados, as autoras concluíram que a pesquisa mostrou a presença de um modelo urbanocêntrico de educação que se distancia dos princípios e concepções que pautam o movimento por uma Educação do Campo no Brasil, revelando a predominância de uma educação orientada por um currículo homogêneo e descolado dos contextos dos estudantes da Educação do Campo.

No artigo "As multisséries no Campo de Arraias-TO: memórias", de Jocyléia Santana dos Santos e Samara Caldas Franco (UFT), as autoras buscam compreender, a partir da metodologia da história oral, as dificuldades encontradas pelos educadores e educandos que vivenciaram a realidade das classes multisseriadas em escolas do campo do município de Arraias, Estado do Tocantins. A pesquisa constatou que a falta de formação específica para o docente atuar na multisseriação, a ausência de um currículo voltado para a realidade do campo e a falta de infraestrutura física, foram os principais aspectos evidenciados.

Em seguida, a partir de uma pesquisa bibliográfica e documental, no artigo intitulado

"A presença da tecnologia na Educação do Campo: mapeamento da produção científica nacional dos últimos cinco anos", de autoria de Vagner Viera de Souza, Elaine Corrêa Pereira e Celiane Costa Machado (FURG), o objetivo do estudo foi realizar um mapeamento das produções científicas brasileiras, dentro da biblioteca digital do SciELO, as quais abordem as temáticas Tecnologia e Educação do Campo. Os autores afirmam que a pesquisa possibilitou compreender quais campos as pesquisas estão mais avançadas em relação às publicações que versam sobre a Tecnologia e Educação do Campo, o que pode vir a atrair novas pesquisas e publicações nestas áreas menos exploradas.

$\mathrm{Na}$ sequência, tem-se o artigo "O Sistema de Organização Modular de Ensino (SOME) na ótica de egressos no município de Breves-Pará", de João Marcelino Pantoja Rodrigues e Gilmar Pereira da Silva (UFPA), que teve o fito de analisar, a partir das percepções de egressos do Ensino Médio, as contribuições e limitações do Sistema de Organização Modular de Ensino (SOME) na formação educacional de jovens do campo no município de Breves, localizado na Ilha do Marajó/Pará. Os resultados da pesquisa demonstraram a afirmação da importância do SOME como única alternativa de acesso ao Ensino Médio para a maioria dos jovens do campo paraense.

O artigo "A Pedagogia da Alternância no contexto da Educação do Campo: a experiência do Instituto Educar", de Luana Bonavigo e Flávia Eloisa Caimi (Instituto Educar e UPF), teve o objetivo de investigar as práticas educativas da alternância desenvolvidas no Instituto Educar, localizado no município de Pontão, Estado do Rio Grande

\begin{tabular}{|l|l|l|l|l|l|l|l|}
\hline Rev. Bras. Educ. Camp. & Tocantinópolis & v. 3 & n. 1 & p. 01-04 & jan./abr. & 2018 & ISSN: 2525-4863 \\
\hline
\end{tabular} 
do Sul. Entre outros resultados, as pesquisadoras constataram que esse Instituto assume uma organização metodológica baseada na Pedagogia da Alternância que envolve o Tempo Escola e o Tempo Comunidade, a qual prioriza a educação dos sujeitos inseridos em uma coletividade e confere protagonismo aos educandos que ali desenvolvem seus processos formativos.

O artigo "Apontamentos sobre a Educação do Campo em Colorado do Oeste/Rondônia: notas de um camponês letrado", de autoria de William Kennedy do Amaral Souza, Raiane Agustinho Lopes, Vanessa Campos de Moraes e Marcos Antônio Oliveira Rodrigues (IFRO, UFSC e UFMT), é o penúltimo trabalho. Realizada no Estado de Rondônia, a pesquisa teve como principal objetivo descrever algumas inquietações sobre a dicotomia existente entre Educação no Campo e Educação do Campo, a partir do Movimento dos Pequenos Agricultores (MPA). Os dados obtidos durante a pesquisa possibilitaram afirmar que as pessoas do MPA acreditam em um sistema educacional melhor, e essa melhora passa pelo diálogo entre Estado e Movimentos Sociais. No caso do MPA, esse diálogo tem como ideia central a valorização da cultura camponesa dentro do ambiente escolar e a garantia da manutenção das escolas do campo, podendo assim, ajudar a diminuir o êxodo rural e, consequentemente, melhorar a qualidade de vida no campo.

Por fim, "O processo de ensino nas escolas multisseriadas do campo e o Programa Escola Ativa", artigo de Marco Túlio Santos Ledo (SEMEC-Almenara), fecha este número da RBEC. Nesse estudo, o objetivo é compreender o processo de ensinoaprendizagem nas escolas multisseriadas do campo, a partir da análise do Programa Escola Ativa. Para tanto, utilizou-se como procedimento de pesquisa a revisão bibliográfica. A pesquisa mostrou que no Programa Escola Ativa as diversas formas de sistematização do trabalho docente e da atuação discente são instrumentalizadas através de práticas já definidas no Projeto Base. Embora esse programa inclua ações importantes para a integração da escola e da família e do aluno na comunidade, muitos fatores não se aplicaram devido a elementos da estrutura organizacional dos sistemas de ensino, como, a não vivência do professor no campo, a falta de formação nos campos universitários que versem sobre o tema, além das dificuldades inerentes à prática docente em turmas multisseriadas.

A Revista Brasileira de Educação do Campo agradece aos(as) autores(as) pela submissão de trabalhos ao periódico e aos(as) avaliadores(as) que contribuíram emitindo pareceres e revisões dos manuscritos apresentados neste número e também ao longo de 2017 e 2018.

Desejamos a todos e a todas boas leituras!

Como citar este editorial / How to cite this editorial

APA:

Silva, C., \& Araújo, G. C (2018). Educação do Campo e pluralidade de saberes. Rev. Bras. Educ. Camp., 3(1), 01-04.

ABNT:

SILVA, C.; ARAÚJO, G. C. Educação do Campo e pluralidade de saberes. Rev. Bras. Educ. Camp., Tocantinópolis, v. 3, n. 1, p. 01-04, 2018.

\section{ORCID}

Cícero da Silva

(iD) https://orcid.org/0000-0001-6071-6711

Gustavo Cunha de Araújo

(iD) https://orcid.org/0000-0002-1996-5959

\begin{tabular}{|l|l|l|l|l|l|l|l|} 
Rev. Bras. Educ. Camp. & Tocantinópolis & v. 3 & n. 1 & p. 01-04 & jan./abr. & 2018 & ISSN: 2525-4863 \\
\hline
\end{tabular} 